\title{
ON FEELING OUT OF PLACE: A CLINICAL CASE
}

\author{
G. Marinho, I. Ganhao \\ Centro Hospitalar Psiquiatrico de Lisboa, Clinic 6, Lisbon, Portugal
}

Objectives:
To reflect on a clinical case.

\section{Background:}

Time, place, significant others and other circumstances coalesce to define human narratives. The sense of belonging and feeling physically and emotionally safe are essential life rafts protective of psychopathology.

Data suggests strong relationships between trauma exposure and psychopathology. The relationship between stressful life events and psychopathology, irrespective of trauma or traumarelated conditions, is less well understood.

Researchers have begun to evaluate the lasting and potentially serious impact that stressful life events or significant experiences in one's life, that involve sudden and lasting change, may produce.

Definitions of stress vary in their foci from objective threatening characteristics of the environment-stressful life events-to individuals' (subjective) appraisals of the threat that an environment poses for them-psychological stress-to the activation of physiological systems that support the behaviours (e.g., fight or flight) needed to respond to that threat.

The stressfulness of an event can be seen as the amount of adaptation or change it requires of an average individual and stressful events as those that are consensually seen as harmful or threatening, when the demand exceedes resources, or events that are threats to one's social status, self-esteem, identity, and physical well-being.

Patients with bipolar disorder report high levels of adverse life events. When compared to individuals without bipolar disorder, those with bipolar disorder report significantly greater past or present exposure to a range of stressful life events. Furthermore, negative social experiences may exacerbate the course of bipolar disorder.

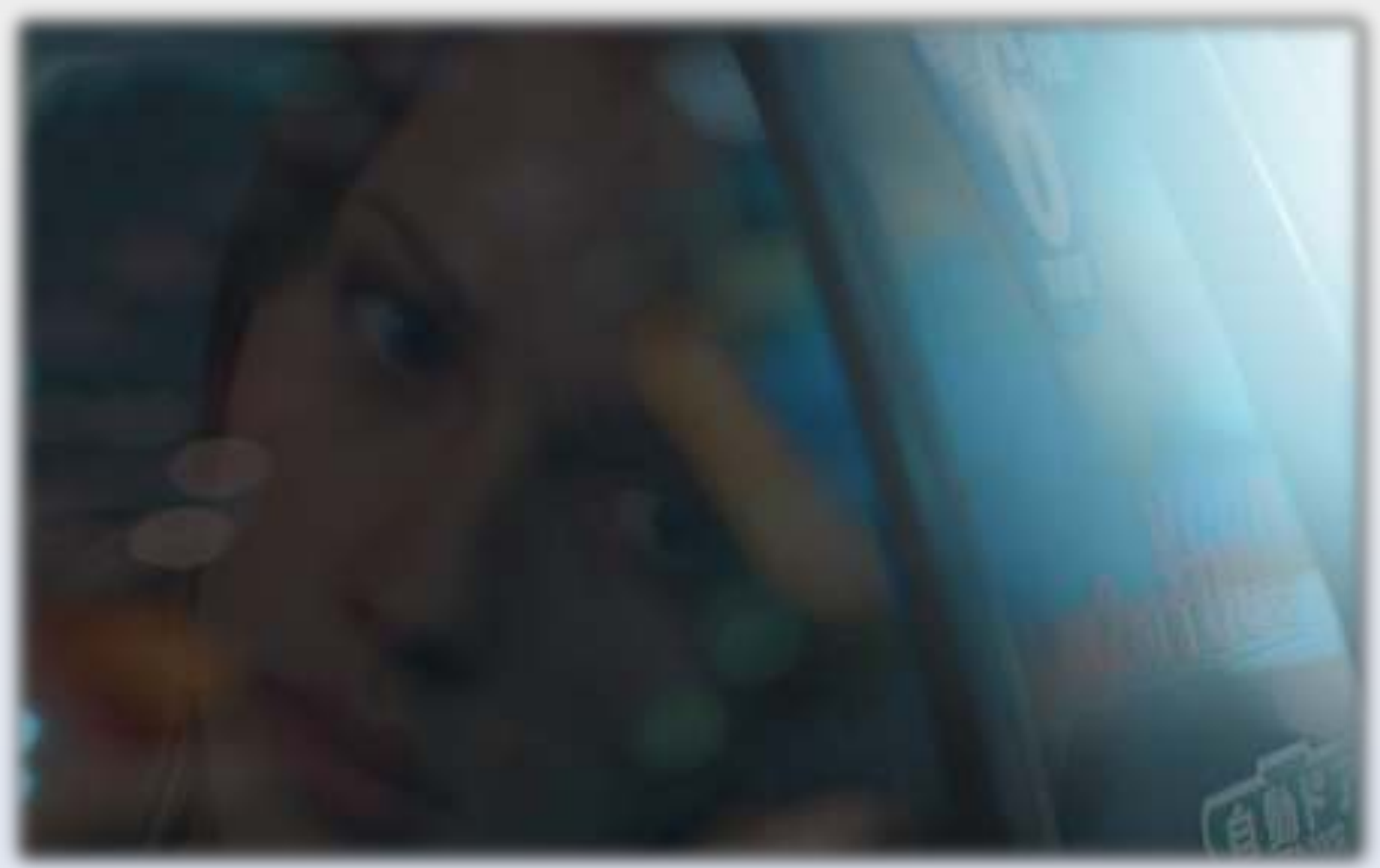

Charlotte: I just don't know what l'm supposed to be.

Bob: You'll figure that out. The more you know who you are and what you want, the less you let things upset you..

Charlotte and Bob, Lost in Translation

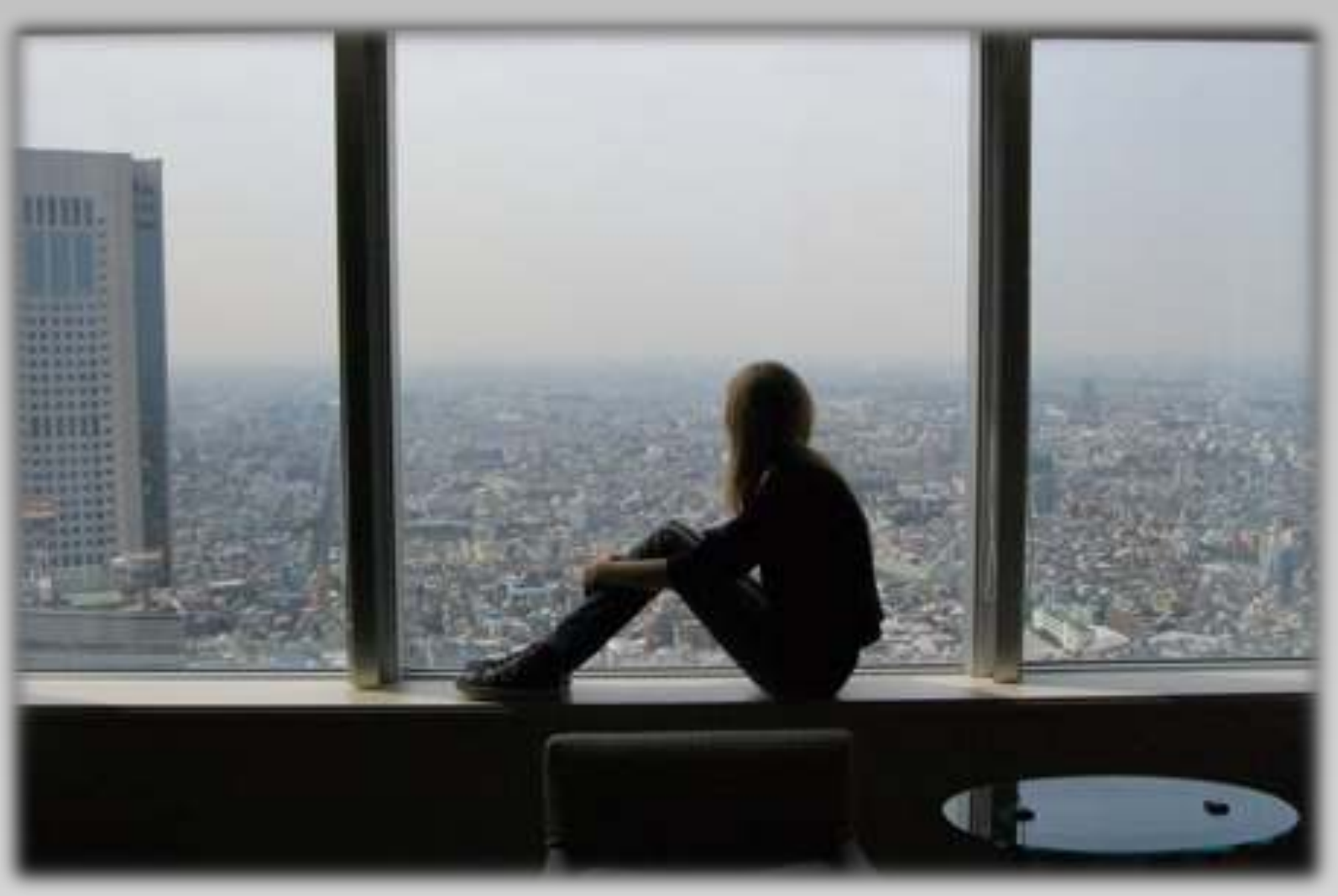

Materials and Methods:

37 year old Brazilian female, who when 18 years old learned her alcoholic father was actually her stepfather, never met her biological father, married a man she considered a friend, on the rebound of a relationship with another man she still loved, was unable to conceive naturally, divorced and travelled a year earlier to attend her twin sister's wedding, planning to stay and restart her life in the United Kingdom, worked as a nanny despite her university degree, struggled to adapt, felt out of place and alone as her sister's life moved on as she was expecting her first child, moved to Belgium with another man she considered just a friend and confronted with his conflicting expectations and difficulty learning a new language moved to Portugal, where she was having trouble adapting to lodging and financial difficulties and cultural differences, a month before being admitted to an inpatient ward due to her first psychotic manic episode, after having been prescribed antidepressants for what had been interpreted as a depressive episode.

\section{Results and Conclusions}

Feeling displaced is expected when moving to a foreign country but perhaps is even more catastrophic when feeling out of place in personal narratives of identity, significant relationships and life purpose, raising the risk of mental illness.

There are still a number of key issues in understanding how stressful events might alter disease pathogenesis.

In general, stressful life events are thought to influence risk of illness through their effects on affect, behaviour, and physiology. These effects include affective dysregulation such as increases in anxiety, fear, and depression. Additionally, behavioural changes occurring as adaptations or coping responses to stressors, such as increased smoking, decreased exercise and sleep, poorer diets, and poorer adherence to medical regimens, provide important pathways through which stressors can influence risk of illness.

Resilience generally refers to the ability of an individual to maintain healthy psychological and physical functioning in the face of exposure to adverse experiences.

What is less clear is whether there are certain types of stressful events for which people tend to show greater resilience than for others. 